\title{
Penis-whirling and Pie-throwing
}

\section{Norm-defying and Norm-setting Drama in the Creative Industries}

Sørensen, Bent Meier; Villadsen, Kaspar

\author{
Document Version \\ Accepted author manuscript \\ Published in: \\ Human Relations \\ DOI: \\ $10.1177 / 0018726717733310$ \\ Publication date: \\ 2018 \\ License \\ Unspecified
}

Citation for published version (APA):

Sørensen, B. M., \& Villadsen, K. (2018). Penis-whirling and Pie-throwing: Norm-defying and Norm-setting Drama in the Creative Industries. Human Relations, 71(8), 1049-1071. https://doi.org/10.1177/0018726717733310

Link to publication in CBS Research Portal

\section{General rights}

Copyright and moral rights for the publications made accessible in the public portal are retained by the authors and/or other copyright owners and it is a condition of accessing publications that users recognise and abide by the legal requirements associated with these rights.

Take down policy

If you believe that this document breaches copyright please contact us (research.lib@cbs.dk) providing details, and we will remove access to the work immediately and investigate your claim. 


\section{Penis-whirling and Pie-throwing: Norm-defying and Norm- setting Drama in the Creative Industries}

\section{Bent Meier Serensen and Kaspar Villadsen}

Journal article (Accepted manuscript*)

\section{Please cite this article as:}

Meier Sørensen, B., \& Villadsen, K. (2018). Penis-whirling and Pie-throwing: Norm-defying and Norm-setting Drama in the Creative Industries. Human Relations, 71(8), 1049-1071. D0I: 10.1177/0018726717733310

\section{DOl: https://doi.org/10.1177/0018726717733310}

Copyright (C) The Author(s) २017. Reprinted by permission of SAGE Publications.

* This version of the article has been accepted for publication and undergone full peer review but has not been through the copyediting, typesetting, pagination and proofreading process, which may lead to differences between this version and the publisher's final version AKA Version of Record.

Uploaded to CBS Research Portal: February २०19 


\title{
Penis-whirling and pie-throwing: Norm-defying and norm-setting drama in the creative industries
}

\author{
[Published online first in: Human Relations, $30^{\text {th }}$ October, 2017]
}

\author{
Bent Meier Sørensen \\ Copenhagen Business School, Denmark
}

\section{Kaspar Villadsen}

Copenhagen Business School, Denmark

\begin{abstract}
This article explores the drama performed around a self-proclaimed 'anti-establishment' executive at a Danish film company, Zentropa. The company prides itself on being against the existing 'elitist' and commercialized Danish film industry. Inspired by the thesis that modern capitalism develops by incorporating the critiques directed against it, the article analyses how Zentropa's Chief Executive Officer invests a 'progressive', counter-cultural spirit in his management practices. We describe how a 'freethinking' and 'subversive' CEO uses his dramatized performances to exercise an authority that violates employees' privacy and involves public displays of disrespect. We further examine how employees use impression management to cope with norm-violating management practices, including sexual provocations and the dramatic, unjustified dismissal of an employee. In the context of these disruptions, we analyse how order is reestablished through dramaturgical cycles of symbolic events, including sacrifice. In particular, the study provides insights into how theatrically staged, norm-defying performances both disrupt the organization and allow managerial power to be reinstituted. It also demonstrates that anti-establishment management involves and rests upon the occasional exercise of traditional managerial hierarchy and control. Theoretically, the article develops a dramatist perspective, combining Goffman's symbolic interactionism and Burke's dramatism to offer a framework for understanding norm-transgressive management in modern organizations.
\end{abstract}

Keywords: Creative industries, dramaturgy, Erving Goffman, film industry, Kenneth Burke, norm-transgression, sacrifice 


\section{Introduction}

What kind of power is at play in a company whose Chief Executive Officer (CEO) identifies himself as rebellious, norm-transgressive and 'against the establishment'? How is order created when he insists that he is breaking down workplace hierarchies, the worn paths of the business establishment and rigid, 'social democratic' labour regulations? In this article, we explore these questions by focusing on a creative sector CEO who stages norm-transgressions, performances he sees as an indispensable driver of cutting-edge creative film production. This CEO, Peter Aalbæk Jensen, founded the Danish film production company Zentropa together with film director Lars von Trier in 1992. Aalbæk maintains that he and his company thrive on criticism: 'See, anybody can criticize me. I have no problem with that!' (Aalbæk in Krasnik, 2013).

Despite abundant reports of norm-transgressions and unpredictable management practices, Zentropa Studios has a discernable social order in its work life. This gives rise to the following question: How can we understand norm-violations not only as an element in the all-too-familiar domains of bullying and harassment (Salin, 2003) but also as a constitutive aspect of Zentropa's management? While the CEO's reported practices are clearly abusive, even reaching levels warranting the term sexual harassment, denouncing these practices is not our primary aim. In critically analysing management this audacious, we would like to ask, first, how this CEO's systematic norm-violations function to create management authority and organizational order, and, second, how our findings and what we will term 'anti-establishment management' might aid in elucidating management at organizations beyond Zentropa.

The managerial interventions of Zentropa's CEO are strikingly dramatized, for which reason we will conceive of all their noisy bluster, their shallowness and cynicism, as 'theatrically staged performances' (Sinha et al., 2012). While Erving Goffman (1959) presents theatre as a metaphor for studying social interaction, we include Kenneth Burke's (1989: 54-55) more radical approach in which life is literally a drama. Accordingly, we view drama as producing the organization by staging order and its ensuing conflicts (Cornelissen, 2004). We intend to explore the premise that order spawns guilt by virtue of its inherent violence - a violence that demands a victim whose sacrifice allows the reinstatement of domination (Burke, 1966). Moreover, Burke's framework offers an explicit normative stance from which we can critically assess such processes. This assessment includes the insight that what we term 'anti-establishment management', paradoxically, appears to be dependent on the continuous, if unpredictable, exercise of traditional or even 
archaic managerial figures.

The article is structured as follows. We begin by briefly describing Zentropa and its CEO, situating them within the Danish creative sector. We then introduce selected concepts from Goffman's work that highlight the ways in which domination and strategies are deployed in social interaction. We complement Goffman by drawing on insights from Burke's dramatism, the combination of which helps us explore how transgressions serve to reestablish order at Zentropa. A subsequent methodology section describes our interpretative framework as well as our selection of data material, which is mostly comprised of secondary sources, and we describe our criteria for selecting events, scenes and actions. We proceed with a brief section that examines Zentropa as an institution, high lighting its rebel identity as a context for norm-violating management practices. On this basis, we analyse three events that took place at Zentropa, each of which differently displays how the organization is enacted through drama. In conclusion, we discuss the extent to which our findings are constructive for understanding how organizational order is produced, and we consider how the notion of anti-establishment management, as well as the dramatist framework developed in this article, can help to theorize management in the ostensibly 'progressive' creative sector and beyond.

\section{Zentropa: The 'revolutionary' film company}

Behind renowned Danish film director Lars von Trier stands his producer and partner, Peter Aalbæk. For instance, while von Trier was causing outrage at the 2011 Cannes Film Festival by expressing apparent sympathy for Hitler, Aalbæk was back in Denmark scandalizing the Danish film milieu by declaring to a tabloid paper that only interns with Zentropa's logo tattooed on their buttocks could get a paid job at the company (Harder, 2009). Unlike von Trier, Aalbæk is a celebrity only in Denmark, but he shares von Trier's entertaining eccentricity, albeit in a more lowbrow version. Every year, Aalbæk parades around the Cannes festival, smoking fat cigars, skinny-dipping in front of the cameras and projecting a generally rowdy presence while the Danish media follows his every move.

In the short documentary film One Day with Peter (Tréhin-Marçot, 2004: Aalbæk's voiceover), Aalbæk explains that his mother 'was a raving anarchist' who rebelled against any kind of authority - the police, schoolteachers, tax authorities. 'I was trained by her', he says. Clearly, Aalbæk identifies himself as having been brought up in an anti-authoritarian spirit. However, a penchant for questioning authority or the establishment is not the only identity that Aalbæk and Zentropa's 
management invoke, as the company claims to be founded on three distinct values: Christianity, communism and capitalism. This triad of apparently incompatible values imbues Zentropa with the image of being an unpredictable and experimental bastard, uncontainable within any established ideologies.

When narrating the birth and history of Zentropa, Aalbæk has often emphasized that the company was formed to counter the dominant film and media establishment at the time. This establishment included the Danish Broadcasting Corporation (DR), the major TV and film production studio Nordic Film and the National Film School of Denmark (Alvarez et al., 2005). According to Aalbæk, these establishments had become a group of self-contained, lazy elites that excluded any newcomers 'unless you were the daughter of a newspaper editor' (Aalbæk in Krasnik, 2013). Aalbæk's goal was nothing less than to revolutionize Danish film.

Self-proclaimed anti-establishment institutions like Zentropa and personalities like Aalbæk have been identified through their rebellion against authorities and entrenched social norms. The term 'establishment' can, according to Zinn (2005: 472), be defined as a mixed social group comprised of a political, economic and cultural elite who collaborate on maintaining the political and economic order: an 'uneasy club of business executives, generals, and politicians'. As such, anti-establishment figures contest ruling elites, promising to tear down the establishment and spearhead major social changes.

Today's management culture has adopted certain values and ideals of the 1968 youth rebellion, including the aesthetic critique of capitalism, as argued by Boltanski and Chiapello (2005). However, while the original 1968 protests were intended to overturn market capitalism, rebelliousness and contestation of received identity now appears to be the very 'motor in changes in the spirit of capitalism' (Boltanski and Chiapello, 2005: 27; see also Costea et al., 2008). The counter-cultural celebration of subversive individuality in a 'Just be yourself mentality is now emblematic of fashionable management discourse (Fleming and Sturdy, 2009). It is against this backdrop that we develop our theo retical framework in the next section. Rather than conceive of our data as manifestations of a given, unified institution, we foreground social interactions in their own right, seek ing analytical resources in social interactionism. This choice is guided by the premise that interaction constitutes a privileged focal point for observing how organizational order is continually disrupted and reestablished.

We pursue two assumptions that arise from the data material. First, under antiestablishment management, order cannot be assumed but is instead strategically 
dismantled and recreated. Second, inspired by Burke, we assume that order and leadership are reinstated at the symbolic level through victimage and sacrifice, and we explore the CEO's dramatic interventions from this perspective.

\section{Social order, transgression and dramatic consistency}

For the purpose of this study, we have developed an interpretive framework that combines analytical tools derived from Goffman's interactionism and Burke's dramatism. While Goffman's work helps us analyse these interactions in their own right, including how order is negotiated in social interaction, Burke's dramatism allows us to describe how transgressions both annul the organization and reestablish a new, if inherently volatile, order. This combination allows us to understand anti-establishment management differently from how it may well understand itself, insofar as we analyse it as a paradoxical duality of order and transgressions of such order.

We wish to approach the management practice under scrutiny as being integral to a particular organiz ational context and play ed out in dynamic social interactions, to which end we draw upon selected concepts in Goffman's work (also explored by Kunda, 1992; Samra-Fredericks, 2004; Down and Reveley, 2009; Biehl-Missal, 2011). Our choice of analytical approach requires the foregrounding of 'impression management', that is:

... the way the individual in ordinary work situations presents himself and his activity to others, the ways in which he guides and controls the impression they form of him, and the kinds of things he may and may not do while sustaining his performance before them. (Goffman, 1959:9)

Through impression management, an individual presents a person that exists only if affirmed in the responses of others (Goffman, 1967: 84-85). The audience defines the meaning of the acts performed, affirming or rejecting the claims conveyed (as well as the person presented) in their visible responses to the performance - a performance being defined as 'a sequence of gestures, postures, verbalizations or actions seen by others (seen, not talked about) and res ponded to' (Manning, 2008: 680). This perspective does not assume a predetermined, enclosed self, since 'often what the individual presents is not himself but a story containing a protagonist who may happen also to be himself (Goffman, 1974: 541). According to Goffman, 'persons' are constructs created and reproduced in social interaction; they are hence the property of situations and institutions, not of 
the individual performer. The expression of a self with particular emotions, say, embarrassment, is, for Goffman, integral to the social interaction in which it occurs. Counter-intuitively, then, the experience of embarrassment 'clearly shows itself to be located not in the individual but in the social system wherein he has his several selves' (Goffman, 1967: 108).

However, actors do not perform any given role automatically, as if following a predefined script; rather, they define themselves in relation to the organizational identity through acts of 'role distance' or 'role embracement' (Goffman, 2005). Generally, role embracement describes a situation wherein the individual completely and wholeheartedly adopts the role that is offered in the situation, displaying this adoption visibly and verbally. At the other end of the spectrum, the performance of role distance expresses a degree of dis-identification between the individual and the role offered to him or her in a specific situation (Goffman, 2005). Moreover, since the roles played out are scripted, the particular scripts that actors follow in particular situations can provide an analytic focus for studying the reproduction of order in organizations. Organization scholars have developed the concept of script to analyse leadership and organizational behaviour (Gioia and Poole, 1984; Bévort and Suddaby, 2016), where the script constitutes a set of guidelines regarding the behaviours found appropriate in the situation. Scripts are rooted in shared cultural meanings, and 'actors "enact" these scripts through relatively habitual or routinized interactions' (Bévort and Suddaby, 2016: 22). In organizational contexts, 'management scripts' structure key activities like meetings, performance assessments and the ways in which managers execute their roles (Bévort and Suddaby, 2016: 22).

Assessing which scripts come to define social interactions begs the question of power, yet Goffman's treatment of power remains by and large implicit (Williams, 1986: 360). However, we find that the concept of 'territories of the self' (Goffman, 1972: 50-87) offers opportunities for studying organizational and managerial relations as asymmetrical and influenced by power. The notion of territories of the self directs attention to how individuals and the space around them can become contaminated or violated because 'an entering other [person] causes the individual to feel encroached upon' (Goffman, 1972: 52). Territories of the self include the skin and clothing, which are accorded differential degrees of concern and respect depending on the context (Goffman, 1972: 62; see also Harding, 2002). Spaces can be organized in a way that prevents individuals from acting with the necessary demeanour, with the effect being that they will not be granted person hood however they perform. Organizations bent on anti-establishment management, we suggest, 
may develop spatial features reminiscent of what Goffman termed 'total institutions' (1976). Such features can be found in military barracks and psychiatric wards, but also in sects and political groups organized around gurus or charismatic leaders. Common to the latter is that the celebration of the leader's sublime authority places the followers in relationships of surveillance and subservience that restrict their possibility of acting with the demeanour of 'persons' in Goffman's sense. It is our assumption that the particular management of space at Zentropa opens up for violations of territories of the self.

By definition, anti-establishment management is premised on disruption. Social interactionism assumes that when the normative order is disrupted (deliberately or inadvertently), participants tend to make immediate, active efforts to restore this order, for example, by showing embarrassment. However, the disruptive logic intrinsic to antiestablishment management challenges this framework, bent as it is on reestablishing order and thus maintaining its principal focus on rituals of respect, deference and self-esteem, as so vividly depicted in Goffman's explorations of the post-war, Anglo-Saxon middle class - a focus that arguably constitutes Goffman's bias of historical-cultural context (Gouldner, 1970). Notably, Goffman cautioned against 'the utter mayhem that would result were the individual to cease to be a gentleman' (1967: 170).

In contrast to the continuous reestablishment of order, anti-establishment management operates with a set of scripts that constantly keeps the possibility of chaos and violations open. Thus, to further engage with the mechanisms of power at play in such dramatized, norm-transgressive management, we turn to drama theorist Kenneth Burke. Supplementing Goffman with Burke expands our analytical possibilities in several ways. While Goffman foregrounded the social order as being stabilized through constant efforts to contain violations, Burke saw social life as a concrete, yet open-ended drama inclined to reinstitute social order through violence. Whereas Goffman largely used the term power to designate individuals' tactics and capacities, Burke conceptualized power as integral to drama itself. Furthermore, Goffman used theatre as a metaphor, whereas Burke (1966) saw the social order as fundamentally established through drama, independent of how that order is analysed. This premise carries a normative component, argues Sinha, since such 'literal perspective' urges the analyst to become a 'critic' who is 'dedicated to the unmasking of any social situation to find the dramas that govern it and to helping the critic engage in the moral activity of appreciating and reflecting on [it]' (2010: 199).

The basic tenet of Burke's dramatism is to approach social order as subjected 
to 'dramatic consistency', the principle that ties any social interaction together as a drama (Burke, 1969; Kärreman, 2001). In this perspective, organization occurs because drama constructs a consistency between its various elements, including actors and stage. Dramatic consistency is, by Burke's account, integral to any order, which implies that it follows a certain sequence: 'If action is to be our key term, then drama; for drama is the cumulative form of action . . . But if drama, then conflict. And if conflict, then victimage' (1966: 54-55). This sequence, argues Burke (1969: 265), contains a perpetual interplay between what he terms 'Order' and the sacrificial 'Kill' of the victim. Social order conceived as drama is hence always on the verge of tragedy, since this order is premised on reproducing 'in all human institutions . . . a reconciliatory murder by means of new vic tims' (Girard, 1987: 53, quoted in Desmond and Kavanagh, 2003: 242). Noting that 'guilt is a principal concern in almost all of Burke's work', Sinha (2010: 197) argues that, in the context of leadership studies, Burke's framework 'can explain how and why loss of face and breach generates guilt within leaders and their followers'.

More specifically, in Sinha and Jackson's (2006) dramatist analysis of leadership, the central, guilt-producing conflict in the leader-follower relation emerges from workers' alienation when subjected to the division of labour. A leader must dispel this alienation through a leadership process that gives workers points of possible identification. Hence, while the division of labour produces distance between the worker and the leader, the identification process is one where "the leader and the follower [potentially] become "substantially one" with a person other than their "self"' (Sinha and Jackson, 2006: 235). This oneness is paradoxical, as any leadership is premised on an alienating order; that is, on there being a certain distance to the leader, yet a leader's influence on followers is premised on identification; that is, on the closure of this distance. Both too much distance and too much identification between leader and follower can collapse the relationship, thus creating conflict and the need for, as Burke asserts, a scapegoat to redeem the inherent guilt arising from the conflict.

Whereas scapegoatism is the necessary form of such organizational drama, any civilization (and any organization) is only possible, Burke further argues, if the killing of the scapegoat is symbolically ritualized and sublimated rather than carried out in real life. The urge to (actually) sacrifice the other as a means of reinstituting order, must therefore constantly be sublimated, as one may find in literature, or be resolved through critical inquiry, as may be seen in social critique (Ercolini, 2003). In literature, killings are transformative 'since the author identifies with the one killed and, subsequently, the killing serves a psychologically cathartic function of 
purging the negative self-associations [i.e., guilt]' (Ercolini, 2003: 216). An example of the sublimated Kill in leadership could be Chrysler CEO Lee lacocca's (in)famous 'sacrifice' of his own salary in order to redeem the company and reestablish his leadership. Such transformations can also be produced by social critique (like this one you are currently reading), when it invokes higher principles and superior orders that can supplant the ones leading to literal Kills (Burke, 1969).

Yet, far from achieving artistic sublimation or being resolved through social critique, the 20th century was marked by a brute fetish for violence and a desire to enhance life by taking it. Startled by this observation, Burke in this case found a possible connection to European existentialism, according to which the perceived lack of meaning in life made life itself appear increasingly absurd. Unsheathed, this line of thinking eventually spurred a 'cult of the Absurd' (Burke, 1969: 265), in which meaninglessness and unavoidable volatility are turned into virtues, altogether celebrating the absurd rather than containing it. In this (existentialist) theatre of the absurd, the universe 'is ruled by surprise, reversal, hallucination, blasphemy, obscenity, and a desire to shock and outrage' (Kellner, 2015: section 3). Anti-establishment management can be seen as a replay of the theatre of the absurd, which in the context of contemporary organizations entails random violations of organizational norms for the sheer sake of disruption. However, more traditional figures of order are essential to Burke's notion of dramatic consistency, which becomes reaffirmed through particular episodes: the boss may dress down and be a comrade against 'the system', yet the overall drama confirms him as the boss nonetheless (Zizek, 2007: 202). Contemporary absurdism, in other words, allows power-holders to cynically sustain their power throughout the chain of absurd events. So, even when episodes apparently break or challenge the principle of dramatic consistency, in so doing they 'accomplish the paradoxical result of obeying its spirit', since the breaking of the principle is 'an ironic gesture. . . that acknowledges the usual rules of the game in breaking them' (Kärreman, 2001: 101). The theatre of the absurd accepts no rules, and yet this mechanism paradoxically allows it to become the rule in any particular organization.

\section{Data and methods}

Our study of norm-transgressive management draws upon a decade's research engagement with Zentropa, focusing on embodied management, leadership ethics and visual company representations (Sørensen and Villadsen, 2015). The current study is based on multiple data sources, including a documentary film, a book on Zentropa, articles in Danish newspapers and magazines, a TV interview and a 
case study visit. No critical studies based on these sources have been undertaken, and only a few are accessible to an international audience. Alvarez et al. (2005) did an institutional analysis comparing Zentropa with other European film production companies, and Pedersen and Pedersen (2008) offered an ethnographic study of Zentropa's branding strategy. Methodologically, our approach differs from these studies in foregrounding management as dramatized, visible performance. Our combination of dramaturgical analysis and social interactionism gives priority to actors' visible and collaborative interaction, basing interpretations principally on this material. The study thus proceeds without using typical organizational research methods such as interviews, exten sive fieldwork or the interpretation of actors' motives.

Two sources have provided particularly rich data for our study. One is a 17-minute documentary film, A Day with Peter, directed by Pablo Tréhin-Marçot (2004). Although short, the film is a visual drama that in itself provides a valuable basis for observing organizational members' practice of impression management and the scripts unfolding at Zentropa. The other is a 25 -minute television interview with Peter Aalbæk, aired on the Danish news programme Deadline (Krasnik, 2013). The programme also cites some criticism levelled at Aalbæk by current and former employees, to which Aalbæk is asked to respond. We have supplemented these filmed performances with participant observations conducted by one of the authors at Zentropa's 20th-anniversary party on 22 June 2012. This visit gave insight into the company's public display of organizational identity during a highly orchestrated and significant company event. A journalist invited the author to the party, which was an open event attended by friends of Zentropa, politicians and prominent figures in the Danish creative sector. The author did not (need to) identify himself as a researcher, so the observations were covert. Another key source of data is Zentropia (Lundtofte, 2013), a detailed documentary book based on a three-year, well-researched field study. The narratives described in the book correspond well with the other sources mentioned and their reports on the inner workings of Zentropa. Aalbæk allowed Lundtofte to participate in company meetings and other daily routines, but refused to comment on the book after its publication (Krasnik, 2013). Although evidently not very happy about the book, neither Aalbæk nor the company has denied any of its substantive claims. However, any events described in this article that might constitute sanctionable violations of Danish labour market laws remain 'claims', as Zentropa has not to date been convicted of any unlawful acts in this regard. Finally, our study draws upon interviews and feature articles published about Zentropa and Peter Aalbæk in 
Danish newspapers and magazines.

First-hand observations are thus not our chief sources. However, our purpose here is not to present 'the unmediated, lived reality' of Zentropa. Paralleling our study in several ways, Sinha et al. (2012) produced an excellent interactionist study of another celebrity, Gary Toomey, the former CEO of Air New Zealand. As in our case, they did not conduct interviews, but carried out their dramaturgical analysis based on secondary sources, acknowledging the possibility that 'a parallel, or different, drama within the organization remained unexamined' (Sinha et al., 2012: 232), as we too must do. Inspired by Sinha et al.'s methodology, we assume that films, TV interviews and media appearances can be legitimate objects of analysis, since they contribute to the symbolic coding of (organizational) reality alongside other visual, discursive and material artifacts (Meyer et al., 2013: 509). Accordingly, we seek to identify the order and disorder produced through dramatic consistency at Zentropa, an approach that includes both representations and social practices as integral parts of the interaction analysed. Taking this approach is not to deny that data material like films displays interactions that are 'staged', dramatized and aestheticized, especially in the context of a film production company. The short documentary about Zentropa's management and the TV interview clearly contain 'performances for the camera' - 'other' versions of reality than, for instance, ethnographic field observations. However, our data indicate that such cinematic performances and their aestheticization are, in fact, a recurring and integral component of Zentropa's film production site.

Our choice of interpretive methodology enables us, first, to describe how roles are performed in selected encounters and, second, to move beyond these performances to the scripts and dramas that produce a consistent order in their own right. While following the principle of dramatic consistency, we will, inspired by Kärreman's instructive reading of organizational dramaturgy, pay particular attention to how 'specific scenes privilege specific agents (and specific acts)' (2001: 100, italics in original). Contradictory scripts may unfold under the aegis of one consistent drama where conflicting views are incorporated, creating a situation in which 'contradictions" are institutionalized' (Hall, 1972: 53). As mentioned, this interpretive framework focuses on moments where dramatized exceptions or norm-transgressions occur and on how order is simultaneously re-inscribed.

More specifically, we used the following criteria to select a series of performances and encounters for closer analysis. First, they should display the CEO's public norm-transgressions reported to have occurred at Zentropa, including his performance of 'authentic character' and his invasions of employees' 
private space. Second, the selected material should show employees' varied responses to the $\mathrm{CEO}$, ranging from embracing the role they were offered to distancing themselves from it. Here, we searched for material that could display the diversified and dynamic nature of employees' situated performances in social encounters with their CEO. During our work process, we recognized that our material posed limits regarding the extent to which we could explore individual employees' oscillations between role embracing and role distancing behaviour.

Our selection strategy can be described as 'purposeful sampling', following Patton's (1990) argument that researchers can purposely select 'information-rich cases' that constitute 'those from which one can learn a great deal about issues of central importance to the purpose of the research' (Patton, 1990: 169). The sampling strategy in our case was guided by a 'controlled opportunism in which researchers take advantage of the uniqueness of a specific case' (Eisenhardt, 1989: 539). The above-mentioned selection criteria determined which of the encounters and role performances available in our data material we examine in the following analysis. In analysing these situated performances, we reconstruct scripts and explore the dramatist consistency characteristic of Zentropa management.

\section{Zentropa's history and identity}

This section provides a brief analysis of Zentropa as an institution, foregrounding its antiestablishment identity. Once the Zentropa identity is elucidated, the CEO's constant concern with adding eccentricism and an anti-establishment character to his managerial role becomes more understandable. In our view, in performing his ostensibly unique, rebellious personality, Aalbæk strives to embody Zentropa as an avant-garde film company. In terms of his self-presentation, Aalbæk perpetually stages a non-conformist self, notably by walking around the office naked, using vulgar language, conducting meetings with his slippered feet on the table and arranging collective skinny-dipping sprees. In Zentropa's day-to-day operations, Aalbæk has also vehemently banned all formal meetings and minutes-keeping, just as he ridicules any formalistic accounting of company operations, financial and otherwise. The only formal workplace gathering is a Friday morning hymn-singing ritual. At the same time, Zentropa remains a successful enterprise in the international film industry, and as 'rebellious' as the company's ethos may be, film production still requires discipline, coordination and routine. Letters still need to be written, proposals submitted, budgets calculated, meetings arranged, contracts concluded, deliveries made, and so forth. Yet, these routines are excluded from 
the company narratives. Zentropa is located in an old military barracks in a Copenhagen suburb, today known as 'Film City'. Aalbæk has arranged his office like a living room, replete with couch and coffee table, signaling informality and the merging of work and leisure. Zentropa's self-identity was on clear display at the company's 20th-anniversary celebration in June 2012. The big bash featured a sadomasochistic freak show, a rock band of transvestites simulating fel latio with pink microphones and stroking dummy genitals, all amplified by the presence of scantily clad young women (escort girls) parading around the pool.

The information obtained about Zentropa's daily operations suggests that norm-transgressions have escalated over the past decade (anonymous employee cited in Krasnik, 2013). In 2008, the previously unchallenged leader of the Danish film industry and Zentropa's erstwhile enemy, the mainstream company Nordic Film, bought half of Zentropa's shares. The escalating transgressions could perhaps be interpreted as an attempt to sustain or defend Zentropa's rebel identity after this acquisition. Several sources claim that Zentropa, especially Aalbæk himself, has systematically crossed employees' personal boundaries to an extent that in less avant-garde contexts would likely generate harassment complaints (Krasnik, 2013; Lundtofte, 2013). Stories of Zentropa interns working full time with no pay but unemployment benefits have been circulating since the company's early days. This delicate situation has been aggravated by the fact that Zentropa is the Danish film studio to have received the most public funding (more than seven million euro since its founding), and allegations of financial irregu larities continue to swirl (Kjær, 2014). Meanwhile, Aalbæk is growing ever more 'eccentric and unpredictable', both within Zentropa itself and in his various public performances (former employee cited in Krasnik, 2013). Against this background we assert that the term 'anti-establishment manager' resonates with Aalbæk's managerial practice. He consistently presents Zentropa as being against the established film industry, and he goes to great lengths to make his actions breach convention. The following empirical accounts will allow us to consider precisely how the management figure that Aalbæk performs can be termed anti-establishment. We note that this figure has certain parallels with Dov Charney, the former CEO of American Apparel (see Moor and Littler, 2008), who was reported to walk around the company half-dressed and solicit sexual encounters with his employees. Unlike Charney, who was charged with harassment and fired, Aalbæk's behaviour is viewed (at least publicly) as more benign, if not actually as a sign of fun, entrepreneurship and even artistry. Yet, as we intend to show, Aalbæk's antiestablishment character is highly unpredictable and paradoxical, as he also often 
wields archetypical establishment symbols - assuming an authoritarian posture with long, Cuban cigars, acting like a priest spreading blessings or declaring himself the instigator of the world's most creative film company. It should be remembered that the establishment ironically often ends up adopting anti-establishment figures; Mick Jagger, for example, was knighted, and Johnny Rotten did commercials for Country Life butter. Challenging authority while simultaneously exercising it is a central aspect of Aalbæk's dramatized performances.

Like Zentropa's mission statements, strategies, charts and records, Aalbæk's performances constitute a key component of how the company speaks about and to itself. His crucial role in instituting or maintaining the company's dramaturgical order (Burke, 1969) will be given key attention in the below analysis. We suggest that Aalbæk often attempts to define situations by integrating disparate and conflicting 'management scripts' into his performances (Bévort and Suddaby, 2016: 22). We further suggest that these scripts are easy to recognize, since they invoke leadership styles familiar in western societies, namely the management scripts distinctive of the congregation (the priest), the company (the boss) and the artistic movement (the avant-garde performer). The following sections bring empirical support to these interpretative suggestions, describing Aalbæk's shifting and unpredictable management practices as well as employees' attempts to calibrate their reactions. The first section centers on violations of employees' territories of self; the second displays Aalbæk's performance of eccentricism and the ensuing embarrassment; and the third highlights a series of absurd events that simultaneously disrupted the organizational order and re-inscribed it. The events progress in severity, moving from embarrassment caused by invasions of private space to outright victimization. In tandem with analysing these events, our vocabulary progresses from Goffman's social interactionism to Burke's dramatism.

\section{Hugging and kissing: Invasions of private space and role distance}

In the 17-minute documentary film One Day with Peter (Tréhin-Marçot, 2004), we follow Aalbæk in a dramatic tour de force with hand-held camera, as he parades through the company site greeting and chatting with employees. This series of encounters can be viewed as constitutive of Zentropa; that is, if we accept the premise that the organization is constituted through encounters and performances, with each performance calling for affirmative reactions from the participants. Witnessing these encounters, we soon realize that the way Aalbæk approaches 
the employees, his salutations and kisses, his boisterous attitude, are - at best tolerated by those who are the objects of his attention. We get the sense that employees acknowledge their role but acquiesce to it grudgingly; they do not participate actively. They do not kiss, shake hands with or engage in conversation with Aalbæk. Rather, they are being kissed (when female), having their hands shaken (when male) and being talked to. Aside from the targeted employee, the employees witnessing these actions participate in the encounters by offering embarrassed smiles or looking away. In such instants, Aalbæk's co-actors affirm the performance of his role as provocateur at the moment they visibly display the expected embarrassment and discomfort.

When Aalbæk stages his own undressing in an office before going skinny-dipping, the (male) staff member deliberately ignores the spectacle, remaining completely unmoved as Aalbæk talks, strips and shakes his penis to the camera. He simply keeps working. When Aalbæk has left, the staff member silently picks up Aalbæk's clothes from the floor and puts them on a hanger. He does not actively participate in the interaction (and its filming), but he immaculately cleans up the office afterwards. Here, Aalbæk seems to invoke the figure of the spontaneous and eccentric artist (who strips naked to set bodily instincts and perceptions free), a performance accentuated by the fact that it occurs right next to a formally dressed office clerk sitting at his desk in front of a bookcase full of binders. A notable aspect of this 'scene', in a Burkean sense, where a certain scene privileges certain events, is that Aalbæk uses it to communicate his authority by having a 'staff of lesser important people that take care of problems of lesser importance' (Kärreman, 2001: 102).

Moreover, the office could be said to constitute a part of the territories of the self, insofar as the separate room with the employee's assigned desk, chair, telephone and other equipment provides accessories that an individual uses to uphold personal demean-our at the workplace. In this perspective, Aalbæk's practice of entering employees' offices and staying there as long as he sees fit, often 'contaminating' the individual through forced interpersonal contact (Goffman, 1976: 35), violates the territory of the self. The employee's choice to distance himself from the assigned role of beholding the spectacle may serve as a protection against a contaminative act that displays disrespect or contempt for the other. Hence, the employee eschews becoming the 'target' or a 'bystander' of the event in Parzefall's and Salin's (2010) sense, instead distancing him self from the role and the script altogether.

Extending these observations, we suggest that Aalbæk's management scripts, 
premised as they are on norm-violations, require the systematic invasion of employees' private space. A general response, visibly adopted by employees confronted with such invasions, is the performance of 'role distance' (Goffman, 2005). Here, employees neither display the anticipated embarrassment nor exit the organization, but rather signal, including through nonverbal means, disdain for or reservation about the script. In Goffman's view, role distancing contains a degree of resistance, as it may 'suggest that the actor possibly has some measure of dissatisfaction from, and resistance against, the role' (Goffman, 2005: 103). Performing role distance, however, is as much a matter of denying the situational role as of displaying that ones' self is not fully expressed in the performed role.

In our case, the employees manifest their role distancing behaviour largely by silently sustaining a position that markedly contrasts the noisy and unpredictable requests of the CEO. On several occasions during his procession through the production site, Aalbæk interferes with employees, forcing prolonged hugs and small talk upon them, while they obviously just want to return to their work. Employees often accede to his exaggerated and excessively lengthy handshakes only unwillingly, and they vainly try to keep their eyes on the screen while doing the shaking. In these situations, the employees' reactions can be located on a spectrum spanning from displays of embarrassment and discomfort to visible, purposeful evasion. While the display of embarrassment still functions to affirm Aalbæk's assumed role as provocateur, the visible detachment can be viewed as role distancing behaviour (bordering on rudeness by those employees who do not actively acknowledge the handshakes). The fact that employees sometimes oscillate between role embracing and role distancing behaviour (displaying embarrassment versus appearing unaffected) is not inconsistent with interactionist assumptions. An actor's attitude in terms of role embracing or distancing behavi our is assumed to arise from the actor's perception of the role expectations and the prevailing definition of the situation (Stebbins, 1967: 250).

The above observations can be considered in light of Goffman's (1967: 91) assertion that some social environments (total institutions being emblematic) may constitute places where personal demeanour is difficult to uphold. Goffman observes that in modern society life's basic activities are differentiated so that 'the individual tends to sleep, play and work in different places with different co-participants'. However, total institutions dissolve 'the barriers ordinarily separating these three spheres of life' (1976: 5-6), as does Zentropa management. While Zentropa and the total institution share the premise that all aspects of life are practiced under the same roof, the two are 'totalizing' on the 
basis of different rationalities. The psychiatric hospital eliminated the personality of inmates in order to normalize them, whereas Zentropa dissolves barriers around employ ees to engender a 'family' around unrestrained creativity. While Aalbæk has a traditional family with wife and children, he states that Zentropa is a family with whom he spends 'much more time', and that he 'loves all of his employees' (Tréhin-Marçot, 2004: voice-over).

All this is integral to the Zentropa spirit and, as such, management deliberately communicates a narrative of ordinary people passionately collaborating and experimenting at work and in their everyday interpersonal interactions. We al ready noticed that the workspace is filled with symbols and acts of informality that reinforce the idea of the organization as a 'working collective' or a 'Zentropa family'. Given that top management strongly propagates this image, employees most likely find it difficult, even risky, to invoke traditional shields of formality like contractual regulations and employee rights, since at Zentropa these structures connote the rigidity of 'bureaucracy'. The following analyses will further elucidate the nature of these challenges.

\section{When the boss helicopters you: Adding character and displaying embarrassment}

Violations of the boundaries between workplace and private life as well as transgressions of the territories of the self are reported to have increased at Zentropa in the last decade. According to one former employee:

Peter [Aalbæk] has become more and more eccentric and unpredictable. He increasingly violates people's privacy. It's often sex-related. He often undresses and performs 'the helicopter' [whirling his penis] right next to younger employees. (Krasnik, 2013)

At an award ceremony for the youngest, unpaid or low-paid interns (called smaitter in Danish, literally small+mats), Aalbæk appeared on stage and positioned himself behind one of the female interns and then proceeded to act out a copulation movement, grabbing her clothes. Extremely upset, she shouted for help while people watched stunned. In the aftermath of the incident, the intern's father threatened Aalbæk with a lawsuit, but it was dropped after the intern was offered a permanent employment contract and 10 hours of psychological counselling (Krasnik, 2013). Notably, in this case mobilizing formal legal ity was covert, as the injured party decided to forego compensation for the offense in the form of a public 
rebuke, a fine or condemnation of her superior's behaviour. Instead, she received compensation through privately negotiated benefits.

As the above incidents show, one of Aalbæk's key managerial performances is to use his own body to invade employees' territories of self and, in the process, to provoke or embarrass them in various ways (Goffman, 1956). Although we have described only a few such events, the CEO's attempts at intimacy appear to permeate Zentropa, insofar as he may manifest this bodily investment at any instant. In one scene of Tréhin-Marçot's (2004) documentary, Aalbæk has kissed a (taller) female employee and moves on to kiss a noticeably shorter one. He then opts instead to pat her on the head and tousle her hair in a gesture not unlike the Catholic ritual of the blessing given by a caring priest, one of Aalbæk's self-proclaimed roles in Zentropa. The group of women offers him laboured smiles while suppressing 'all signs of shame and embarrassment' (Goffman, 1956: 270), immediately returning to their tasks and escaping the awkward and patronizing situation. The women clearly act vicariously on Aalbæk's account and, in Goffman's poignant wording, 'blush with and for him', as he himself does not 'have sufficient sense of shame or appreciation of the circumstances to blush on his own account' (1956: 265).

Faced with the recurrent demand to perform embarrassment, one strategy for employees could be to erect formal barriers; for example, asserting their legal rights under harassment or labour laws, with all the potential career risks. Indeed, formal rights and regulations are a part of those 'rigid, social democratic structures' that Aalbæk disdains, since they constrain creativity. Here, Burke's principle of dramatic consistency demonstrates the difficulty of mobilizing such formality, since it emphasizes the privileging of specific acts by specific scenes (Kärreman, 2001: 100). As noted, Aalbæk generally creates stages that signal informality, such as an office with a sofa bed where he naps before meetings. His recurrent hugs (rather than handshakes) and collective sauna visits fall in the same category. Such encounters seem to call for the participants to perform as spontaneous and authentic individuals, not as contracted employees.

We have already associated Albæk's leadership practices with research on bullying, harassment and transgression (Salin, 2003). Placing this assessment within Burke's dramatism, we can understand the transgressions as an answer to the problem of alienation, or distance, caused by the division of labour (Burke, 1965). In Sinha and Jackson's (2006: 236) reading of dramatism, this problem arises from the paradox of exercising leadership - that one must navigate distance and identification at the same time, achieve identification between leader and 
follower yet maintain the distance that serves to uphold the superiority intrinsic to being a leader. This follows from the premise that management essentially requires some form of established order that, argues Grint (2010), entails upholding a 'sacred' distance between leader and follower.

In the specific context of Zentropa, leadership distance (i.e. the distinction between the formal role and the created 'scene' of leadership) constantly dissolves. Time and again Aalbæk advances so close to his employees as to annul his status as leader, only to abruptly retreat into a lofty distance, where he, as we shall see, invokes 'traditional virtues'. When the distance between the leader and his followers occasionally dissolves, we observe an invasive investment of Aalbæk's body in his managerial practices. This includes his (quite literal) heaving of employees' bodies into his own, and may be understood as an attempt to incite an identification process of becoming unified, or 'substantially one' (Sinha and Jackson, 2006: 236).

In Aalbæk's view, the need for unrestrained spontaneity and creativity justifies his norm-violating and vulgar antics, and it is this view that makes taking a critical stance against such management practices so hard. Aalbæk's impression management relies in great part on creating the display of 'creative instigator', a person driven by raw impulses that escape rationality and spurn the formality of the bureaucrat. When asked about the potentially damaging effects of violating employees' limits, Aalbæk replies: 'I am who I am. It is only by being who I am that I can push Danish film forward!' (Krasnik, 2013). We suggest that a key message enacted in Aalbæk's impression management is that hovering just beneath the for mal role is a spontaneous self, a creative force just waiting to be unleashed. Aalbæk's recurring sexual provocations, audaciously public as they are, can thus be viewed as staged expressions of impulsiveness and originality that promise to transfer these qualities to the employees. It should be emphasized here that the transgressions observed at Zentropa, the violations of privacy, do not occur covertly in the storage room or the late hours of the Christmas party (although we cannot know if this may happen) but are utterly explicit everyday routines on public display for all. They are an integral part of the dramaturgical scripts that have become routine in the halls of Zentropa. While it may be surprising that so few complaints have been filed, we have suggested that invoking contracts and formal rights as defined by labour law is irreconcilable with the acclaimed Zentropa identity.

\section{The custard pie gag: Role-embracement and victimage}


Our third, and last, event focuses on an encounter where contradictory dramaturgical scripts appear to become institutionalized within Zentropa (Hall, 1972). Our analysis incorporates Burke's (1989) insights about conflict, guilt and victimage as essential to the (re)establishment of social order. We recall that this happens through a 'dramatic consistency' that defines rules integral to dramaturgical scripts. However, the enactment of scripts is often fundamentally at odds with the structure of an organization's formal roles and rules. In this final encounter, the young intern Lisa Overgaard (anonymized for this article) works in the company's music department. One day Aalbæk invites her to go skinny-dipping - in midwinter - with himself and Lars von Trier. Overgaard refuses the invitation as politely as possible (Lundtofte, 2013: 160). Aalbæk, for his part, refuses to take no for an answer:

Aalbæk: If you don'tjoin us, l'll have to fire you.

Overgaard: Then you'll have to fire me.

[Aalbæk resolutely walks into the company's main hall, where employees are having lunch.]

\section{Aalbæk [shouting]: Write a termination letter, FIRE THAT BITCH!}

At first glance, this seems to be a straightforward incidence of the CEO making a unilateral executive decision, reminiscent of Eisenhardt and Bourgeois' (1988: 743) seminal study of decision making, when the director Geoff 'makes a decision, it's like God'. While Aalbæk frequently enacts roles akin to an almighty sovereign, we see this not simply as an incident in which the classical hierarchy (of bureaucratic, patriarchal, or despotic structures) is affirmed when a subordinate violates the organizational order and is then disciplined through the execution of power. On closer inspection, Aalbæk is not merely making an isolated decision; instead, the decision marks the beginning of a new staging of events that opens up for something more fundamental, indeed sacred, to happen, a staging that includes putting his own position at stake (if not exactly at risk). Recall here Burke's (1989: 280) cyclical formula for organization as one of 'order', 'guilt', 'need for redemp tion' and 'victimage'. Hence, after the widely publicized message of Overgaard's dismissal, Aalbæk hesitates to carry out the firing. The audience (the rest of the employees) could interpret this hesitation as him having second thoughts. The problem appears to be that the victim, the 'bitch', is actually innocent, even within the bizarre logic of Zentropa. After all, her sin was merely to have rejected the 
invitation to go skinny-dipping with her bosses. She is guilty of no more than role distancing (Goffman, 1976: 94), as she never embraced the role expectations in the script performed by her superiors.

The dismissal turns out not to materialize (yet), and Overgaard's colleagues in Zentropa's legal office later assure her that 'Peter is just testing' her. Subsequently, Aalbæk speaks with Overgaard, and although he vaguely confirms the dismissal, he stays true to his provocative managerial style and invites her to find a 'creative solution' to her situation. In our Burkean optic, this incident can be seen as Aalbæk's attempt to cope with the diffuse 'guilt' that clings to his handling of the situation and the organization's subsequent 'need for redemption' in this regard. If power is to be respected beyond the scope of its brute force ('FIRE THAT BITCH!'), it must be couched in a ritual in which violence is not just haphazard and unpredictable, but produces, through dramatic consistency, some measure of order. In other words, within the drama and beyond the law, the person sacrificed must be rendered guilty: Overgaard is not guilty (yet), hence the continued 'testing'. While Aalbæk clearly crosses lines, he is still bound by the demand for dramatic consistency, a demand that in this instance implies that the sacrificial victim must be recognizable as guilty. Thus, in terms of the "creative solution' requested, this solution could, as Aalbæk himself suggests, imply either the force of law or simple violence; that is, 'filing a lawsuit or getting ten gangsters to beat [him] up' (Lundtofte, 2013: 165). Overgaard considers buying Aalbæk a lap dance or a Lolita doll for the morning song, a ritual used earlier as a comeback to the CEO (Lundtofte, 2013: 157). If Overgaard previously refused to embrace her role in the skinny-dipping ritual, she now appears to embrace her role in the counterstrike against Aalbæk, going all-out to find a truly 'creative solution' to his putting her on the spot. Eventually, she decides on a classic gag: throwing a custard pie in Aalbæk's face at some public occasion.

As we see the drama unfolding before our eyes, we should not be surprised to learn that when Overgaard actually embraces her assigned counter-striking role, this role's function in the dramaturgical order of conflict, guilt and victimage is revealed. The role now brazenly embraces her (Goffman, 2005: 94), and after having thrown the custard pie at Aalbæk during a morning staff meeting, she is told by a member of his legal staff that the CEO did not find the episode funny:

Legal staff member: [Aalbæk] is after all a man of traditional virtues . . He doesn't appreciate when the young thumb their noses at their superiors.

Overgaard: Are you firing me for having thrown a custard pie in Aalbæk's face? 
Staff member: Yes, we are firing you according to Section 224 of the Criminal Code, 'Minor violence against a manager'.

In reality, there exists no such provision regarding 'minor violence against a manager'. Section 224 of the Danish Criminal Code actually concerns prostitution. Ironically, the assumption that Overgaard should go skinny-dipping with her bosses (and her first dismissal when she refuses to embrace this role) seems to rely on the premise that her employment relation is actually one of prostitution. While the very existence of a 'legal department' at Zentropa is in itself rather absurd given the 'no rules apply' context, the pie-throwing stunt also suggests that parody is one way of interacting with this type of management. After all, the pie in the face is emblematic of the silent movie epoch. Hence, while the act vividly over-identifies with Aalbæk's own theatrical stunts, it respects the genre of the film industry. While Overgaard's actions cannot be recognized within the formal organizational rules - a fake section of the Criminal Code has to be invented they still play an integral part in achieving dramatic consistency throughout the script. Rather than understanding this act as a volitional and individual 'answer' to Aalbæk, one must see it as a necessary part of the dramatic sequence.

Now the ritual of creating order out of violence has come full circle. While turning an incident of 'minor violence against a manager' into a legal case against Overgaard is absurd well beyond Kafka, violence remains the substance of the process. What has happened is that the diffuse guilt connected to the public dismissal has now found its body: the custard pie attack has served the function of moving the guilt from the body of the executive to that of the employee, from Aalbæk to Overgaard. It is she who threw the custard pie; it is she who humiliated the sovereign 'man of traditional virtues'. It is she who must die. The temporary solution to reestablishing order is to sacrifice Overgaard as a scapegoat (Girard, 1987). In the logic of victimage, Overgaard now finally becomes the scapegoat that saves Aalbæk's face, a face he lost more painfully in the skinny-dipping episode than when he literally got it covered with custard pie. In the skinny-dipping episode, a younger woman rejected the two older males' insistence on a quasi-sexualized ritual of nakedness and intimacy, a rejection that becomes a strike against top management's perceived potency and a strike which, ultimately, would be impossible to punish by invoking a (fictitious) legal code. It was this first rejection that spurred the bitter conflict, not the retaliation. The latter only created the custard pie scene in which the impotency of the first conflict became transformed into a specified aggression - a 'minor violence' - against which legal scripts 
(whether existing or invented laws) could be mobilized. This final part of the ritual is what Burke (1969: 265) refers to as the redemptive 'Kill', the remedy against havoc that recuperates the disruption into a normative order (however unpredictable and fragile this order in the present case actually is).

We see that perpetuating the practice of rule-breaking opens up for absurdity: Zentropa as a scene continuously privileges what Burke (1969: 265) refers to as the 'cult of the Absurd'. The process leading to the dismissal of Overgaard must appear mesmerizingly and grossly absurd to the victim herself, and the parallels between this drama and the theatre of the absurd are obvious. Management at Zentropa is fundamentally constituted through unpredictability, for both its logic and virtue create an organization pervaded, as in absurd theatre, not only by surprises and reversals but also by blasphemy and obscenity - indeed, in Aalbæk's performances, by a constant 'desire to shock and outrage' (Kellner, 2015: section 3). Unsurprisingly, the newly established order - that is, Overgaard's exit from Zentropa - is followed by the injunction to a new Kill. On a later occasion, after the de jure dismissal has been effectuated, Aalbæk has a conversation with Overgaard in which he invites her - once she has become a strong player in the film industry outside Zentropa - to come back and 'destroy' him, just as he earlier 'destroyed Nordic Film' (Lundtofte, 2013).

This logic implies a continuation of (more or less) redemptive sacrifices in the Danish film industry. Contrast here Aalbæk's literal Kill of Overgaard (we conceive of an unjustified dismissal as a literal Kill) with her own version of the Kill: the custard pie attack, which was exactly what Burke understands as a sublimated Kill (i.e. a carnivalesque conversion of order through a humorous transgression rather than, say, harassment or violence). Yet, the 'cult of the Absurd', as orchestrated by the CEO, negated Overgaard's sublime trajectory, a trajectory that suggests 'the move to a higher order that serves as an organizing principle' (Ercolini, 2003: 219). This lack of any principle of higher order motivates us to suggest that Zentropa's overall managerial script is couched in 'the cult of the Absurd'. In this volatile, absurd order, any 'Kill' (transgression, humiliation, firing, etc.) is to be carried out literally, rather than sublimated into a more refined and, above all, predictable and lasting order.

\section{Discussion and further perspectives}

Taken together, our analyses reconstruct anti-establishment management as an at times extremely volatile, unpredictable and resource-intensive practice. At the same time, its dramatic cycles continuously invoke much better-established 
managerial structures. In terms of our individual contribution, we noticed that anti-establishment disruptions were accompanied by surprisingly authoritarian and controlling practices, which, in turn, sustained a certain organizational status quo. In the dramatic scripts of Zentropa, we found a routinization of paradoxical scripts that tended to overshadow and replace traditional managerial roles. In a Burkean perspective, it is indeed this routinization of paradoxical scripts that paves the way for organizations (and societies) to become engulfed in the theatre of the absurd, including its celebrations of unpredictability and literal Kills. We see this perhaps most vividly staged in our last encounter, where Aalbæk prohibits the script he himself has orchestrated - that of inviting Overgaard to answer his challenge from ultimately being played out. Instead of facing the pie-throwing gag on its own terms, for instance as a sublime transformation of violence into comedy, he abruptly oscillates into a (bogus) legal management script, thereby confirming the dramatic consistency of Zentropa being de facto premised on unpredictability and victimage.

We have witnessed how Aalbæk's management style, as progressively characterized throughout the above interpretations, disrupts existing categories and distinctions operationalized by 'stable, conventional, executive' views of management by turning them 'upside down' or making them precarious.' Somewhat understating the matter, we can, with Goffman (1967: 170), say that, in ceasing 'to be a gentleman', Aalbæk also ceases to be an executive in the traditional sense of a figure that maintains a stable role to which expectations can be assigned under the assumption of predictability (Marion and Uhl-Bien, 2002). Yet, the carnivalesque event of pie-throwing, rather predictably perhaps, is annulled as the role and expectations of 'a man of traditional virtues' descend into despotism and sacrifice.

While the very concept of 'anti-establishment management' is, strictly speaking, an oxymoron, examining its practice reveals it as a controlled, if demanding, balance between staged rebellion against conventions, on the one hand, and a regression to conventional hierarchy and, at times, archaic leaders hip authority, on the other. The annulment of predictability and the ensuing disappearance of moral order is in our estimation the critical issue here. All three analysed incidents evince how for those involved it 'becomes difficult to separate manipulation from morality' (Sinha and Jackson, 2006: 242). Under the 'cult of the Absurd', moral guiding points cannot be maintained outside the cult, since morality itself is created through the dramaturgical script. In other words, from within the drama - that is, within Zentropa - the absurd theatre makes it difficult to see the events from a 
moral perspective, let alone a contractual or legal one. Moreover, as Grint (2010) observes, leadership can only be effectively sustained when some measure of formalized distance and visible difference between leader and employees is maintained. As Aalbæk flouts a number of these differences - the one between his own body and his employees' territories of self, for instance - he also flouts the difference between sustaining the organization as an entity premised on 'a distinctive normative order' (Scott, 1992: 187), letting it disintegrate into a kind of (measured and controlled) moral chaos.

More generally, and beyond Zentropa, the current management vogue calls for decentered, egalitarian organizational structures where employees are expected to fully engage as persons rather than as contracted labour. Such a trend is evident in prevalent slogans like 'express yourself and 'do what you love', and can be identified in subjectivation strategies that draw 'private' practices into the workplace (Fleming and Spicer, 2004; Fleming and Sturdy, 2009). This development also includes a stronger managerial emphasis on performative expressions that signal infinite potentiality and creative excess (Costea et al., 2007). Our study adds to this research and extends it by foregrounding the unpredictable and precarious potentials entailed when work life is orchestrated to abandon formality and unleash authentic human creativity. We have further sought to conceptualize the power effects inherent in the oscillations between incongruous managerial scripts and the spectacular, but seemingly absurd, drama instigated by the CEO. Whereas Fleming and Spicer's (2004) seminal study of culture management demonstrated how employees' responses to such a spectacle ranged from enthusiasm to scepticism, or even cynicism, our case showed that whether one plays against or within the script, one may end up being sacrificed. The ways in which such logic of dramatic consistency is evoked in a management practice bent on disrupting the organization and re-instituting order is a distinct finding from the Zentropa case.

In terms of methodology, our study extends recent organizational research that relies on dramatist approaches, and is based on secondary sources that focus on 'media-reported organizational drama' (Sinha et al., 2012: 239; see also Patriotta and Spedale, 2009). Drawing on this inspiration, we developed a perspective akin to that of 'a theatre critic' who is able to observe 'reflectively from a distance' and evaluate 'performances against his or her own criteria' (Sinha et al., 2012: 239). With Burke (1969: 265), we identified a 'cult of the Absurd', where paradoxical, managerial scripts led to boisterous spectacles and victimage, if only eventually to affirm conventional forms of hierarchical order. 
While more dramas certainly could be discovered than those that have been filmed, edited and reported, we believe our dramatist method may go beyond Zentropa and have relevance for other organizations in which delegation, project orientation and individual commitment take precedence over formal structures, specified roles and stable hierarchies. Subjected to an anti-establishment manager, order cannot, as we initially assumed, be taken for granted, although it ultimately prevails. The confirmation of this assumption relies heavily on what we, with Goffman, termed the scripting of situations that involved invasions of employees' territories of self and other transgressive management practices as well as employees' concomitant exposure to unpredictability and absurdity. Exploring our other assumption - that order is recreated through either sublimated or literal 'Kills'

- we identified instances in which disruptive attempts to spur norm -transgressions led to crisis, guilt and victimage and eventually regressed into managerial control

and dominance. Here, Burke's dramatism allowed us to analyse as well as normatively assess the practices observed.

\section{Conclusion}

Theatrical performances are, of course, found at places other than Zentropa. When Steve Ballmer famously danced and cried in front of thousands of Microsoft employees at his exit from the company, and LEGO CEO Jørgen Vig Knudstorp sang and danced during the annual financial reporting, these performances, along with Aalbæk's, constitute a possible trend toward absurd corporate theatre. In our effort to explore such a trend, we have analysed a number of management scripts at Zentropa, initiated by the CEO by way of his very distinct performances. We identified repeated violations of territories of the self and explored how the organization was enacted and cyclically reestablished through more dramatic acts of victimage. The study thus foregrounded how organizational order was affirmed through dramaturgic performances governed by dramatic consistency, a process that implied overriding formal structures, employment contracts or organizing according to functionality. Our study has further developed the concept of anti-establishment management, a concept that we have sought to give empirical substance, submit to critical assessment and assign analytical potential. We offered empirical accounts of what dramatized anti-establishment management practices may involve, and we discussed how violations of conventional manners and respect of privacy can become, if not exactly legitimized, then rendered contextually meaningful. To make sense of our observations, we developed a 
combination of social interactionism and dramaturgical analysis. It is this framework that we hope to offer for further case studies that explore norm-transgressions and how they may be normalized in contemporary organizations. This kind of analytical framework may prove useful for further investigating the practices of those managers who seek to be experimental, spontaneous and norm-defying. 


\section{Funding}

This research received no specific grant from any funding agencyin the public, commercial, or not-for-profit sectors.

\section{Note}

We wish to thank one of our tireless reviewers for this succinct observation.

\section{References}

Alvarez JL, Mazza C and Strandgaard Pedersen J (2005) Shielding idiosyncrasy from future isomorphic pressures: Towards optimal distinctiveness in European filmmaking. Organization 12(6): 863-888.

Bévort F and Suddaby R (2016) Scripting professional identities: How individuals make sense of contradictory institutional logics. Journal of Professions and Organization 3(1): 17-38.

Biehl-Missal B (2011) Business is show business: Management presentations as performance. Journal of Management Studies 48(3): 619-645.

Boltanski L and Chiapello È (2005) The New Spirit of Capitalism. New York: Verso. Burke K (1965) Permanence and Change: An Anatomy of Purpose. Indianapolis, IN: Bobbs-Merrill.

Burke K (1966) Language as Symbolic Action. Berkeley, CA: University of California Press. Burke K (1969) A Rhetoric of Motives. Berkeley, CA: University of California Press.

Burke K (1989) On Symbols and Society. Chicago, IL: University of Chicago Press.

Cornelissen JP (2004) What are we playing at? Theatre, organization, and the use of metaphor.

Organization Studies 25(5): 705-726.

Costea B, Crump N and Amiridis K (2007) Managerialism and 'infinite human resourcefulness': A commentary on the 'therapeutic habitus', 'derecognition of finitude' and the modern sense of self. Journal for Cultural Research 11(3): 245.

Costea B, Crump N and Amiridis K (2008) Managerialism, the therapeutic habitus and the self in contemporary organizing. Human Relations 61(5): 661-685.

Desmond J and Kavanagh D (2003) Organization as containment of acquisitive mimetic rivalry: The contribution of Rene Girard. Culture \& Organization 9(4): 239-251.

Down S and Reveley J (2009) Between narration and interaction: Situating first-line supervisor identity work. Human Relations 62(3): 379-401. 
Eisenhardt KM (1989) Building theories from case study research. Academy of Management Review 14(1): 532-550.

Eisenhardt KM and Bourgeois LJ (1988) Politics of strategic decision making in high-velocity environments: Toward a midrange theory. Academy Of Management Journal 31(4): 737-770.

Ercolini GL (2003) Burke Contra Kierkegaard. Philosophy and Rhetoric 36(3): 207-222.

Fleming P and Spicer A (2004) 'You can check out anytime, but you can never leave': Spatial boundaries in a high commitment organization. Human Relations 57(1): 75-94.

Fleming $\mathrm{P}$ and Sturdy A (2009) Just be yourself! Employee Relations 31(6): 569-583.

Gioia DA and Poole PP (1984) Scripts in organizational behavior. Academy of Management Review 9(3): 449-459.

Girard R (1987) Things Hidden Since the Foundation of the World. Stanford, CA: Stanford University Press.

Goffman E (1956) Embarrassment and social organization. American Journal of Sociology 62(3): 264-271.

Goffman E (1959) The Presentation of Self in Everyday Life. Garden City, NY: Anchor Books.

Goffman E (1967) Interaction Ritual. Garden City, NY: Doubleday.

Goffman E (1972) Relations in Public. Harmondsworth: Penguin.

Goffman E (1974) Frame-analysis. New York: Harper and Row.

Goffman E (1976) Asylums: Essays on the Social Situation of Mental Patients and Other Inmates. Harmondsworth: Penguin.

Goffman E (2005) Role distance. In: Brissett D and Edgley C (eds) Life as Theater: A Dramaturgical Sourcebook. New Brunswick, NJ: Transaction Publishers, pp. 101-112.

Gouldner A (1970) The Coming Crisis of Western Sociology. New York: Basic Books.

Grint K (2010) The sacred in leadership: Separation, sacrifice and silence. Organization Studies 31(1): 89-107. 
Hall PM (1972) A symbolic interactionist analysis of politics. In: Effrat A (ed.) Perspectives in Political Sociology. New York: Ardent Media, pp. 35-76.

Harder T (2009) Aalbæks elev-tatoveringer forarger. Ekstrabladet, 22 September. Available at: http://ekstrabladet.dk/nationen/article4204598.ece (accessed 5 May 2017).

Harding N (2002) On the manager's body as an aesthetic of control. Journal of Critical Postmodern Organization Science 2(1): 63-76.

Kärreman D (2001) The scripted organization: Dramaturgy from Burke to Baudrillard. In: Westwood R and Linstead S (eds) The Language of Organization. London: SAGE, 89-111.

Kellner D (2015) Jean Baudrillard. In: Zalta EN (ed.) The Stanford Encyclopedia of Philosophy.

A vailable

at: http://plato.stanford.edu/archives/win2015/entries/baudrillard/ (accessed 5 May 2017).

Kjær B (2014) Filminstitut sætter Zentropa under skærpet tilsyn. Politiken, 26 May. Available http://politiken.dk/kultur/filmogt v/art5517527/Filminstitut-s\%C3\%A6tter-Zentropa-un dersk\%C3\%A6rpet-tilsyn (accessed 5 May 2017).

Krasnik M (2013) Interview with Peter Aalbæk. Deadline, TV channel DR2, 13 May. Available at: https://www.youtube.com/watch?v=omdO1OIQE 80 (accessed 5 May 2017).

Kunda G (1992) Engineering Culture: Control and Commitment in a High-Tech Corporation. Philadelphia, PA: Temple University Press.

Lundtofte AM (2013) Zentropia. Copenhagen: Gyldendal.

Manning PK (2008) Goffman on organizations. Organization Studies 29(5): 677-699.

Marion R and Uhl-Bien M (2002) Leadership in complex organizations. The Leadership Quarterly 12(4): 389-418.

Meyer RE, Höllerer MA, Jancsary D and Van Leeuwen T (2013) The visual dimension in organizing, organization, and organization research. The Academy of Management Annals 7(1): 487-553.

Moor L and Littler J (2008) Fourth worlds and neo-fordism: American aparel and the cultural economy of consumer anxiety. Cultural Studies 22(5): 700-723.

Parzefall M and Salin DM (2010) Perceptions of and reactions to workplace bullying: A social exchange perspective. Human Relations 63(6): 761-780. 
Patriotta G and Spedale S (2009) Making sense through face: Identity and social interaction in a consultancy task force. Organization Studies 30(11): 1227-1248.

Patton MQ (1990) Qualitative Research and Evaluation Methods, 2nd edn. Thousand Oaks, CA: SAGE.

Pedersen AR and Pedersen JS (2008) The role of the media in the co-production of identities in a

filmmaking company. Tamara 7(1): 91-108.

Salin D (2003) Ways of explaining workplace bullying. Human Relations 56(10): 1213-1232.

Samra-Fredericks D (2004) Managerial elites making rhetorical and linguistic 'moves' for a moving (emotional) display. Human Relations 57(9): 1103-1143.

Scott WR (1992) Organizations: Rational, Natural, and Open Systems. Upper Saddle River, NJ: Prentice Hall.

Sinha PN (2010) The dramatic genre in leadership studies: Implications for research and practice. Leadership 6(2): 185-205.

Sinha PN and Jackson B (2006) A Burkean inquiry into leader-follower identification motives. Culture \& Organization 12(3): 233-247.

Sinha PN, Inkson K and Barker JR (2012) Committed to a failing strategy:

Celebrity CEO, intermediaries, media and stakeholders in a co-created drama.

Organization Studies 33(2): 223-245.

Stebbins RA (1967) A note on the concept of role distance. American Journal of Sociology 73(2): 247-250.

Sørensen BM and Villadsen K (2015) The naked manager: The ethical practice of an anti-establishment boss. Organization 22(2): 251-268. Tréhin-Marçot P (2004) One Day with Peter. Copenhagen: Zentropa Productions.

Williams SJ (1986) Appraising Goffman. British Journal of Sociology 37(3): 348-369. Zinn H (2005) A People's History of the United States, 1492-Present. New York: Harper Perennial.

Zizek S (2007) In Defense of Lost Causes. New York: Verso.

\section{Authors}

Bent Meier Sørensen is Professor in Organizational Philosophy at Copenhagen Business School, Denmark. He is currently leading a research project on sustainable entrepreneurship supported by the Velux Foundation. Sørensen's key 
research themes include entrepreneurship, organizational aesthetics, theology and poststructuralist philosophy. He has published in journals like Organization Studies, Organization, Management Learning and Culture and Organization. Sørensen is also part of the editorial collective of the journal Ephemera. [Email: bem.mpp@cbs.dk]

Kaspar Villadsen is Professor at the Department of Management, Politics and Philosophy, Copenhagen Business School, Denmark. His research revolves around Michel Foucault's authorship, technology, organizations and the relationship between state and civil society. He has recently published the book State Phobia and Civil Society (with Mitchell Dean, Stanford University Press). Villadsen's work has appeared in journals like Economy and Society, Theory, Culture \& Society, Organization and Body \& Society. [Email: kv.mpp@cbs.dk] 